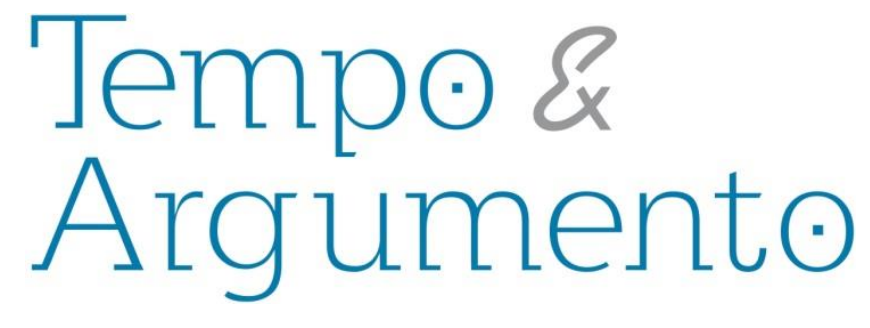

\title{
Escrita de si e história da historiografia
}

\section{Resenha da obra:}

GARCIA, Patrick. Les présents de l'historien. Paris: Publications de la Sorbonne, 2014, 221 p. (Collection "Itinéraires", 6)

Autor:

Raphael Guilherme de Carvalho

Doutorando no Programa de Pós-graduação em História

da Universidade Federal do Paraná (PGHIS/UFPR).

Brasil

raphaelguilherme83@gmail.com

\section{Para citar esta resenha:}

CARVALHO, Raphael Guilherme de. Escrita de si e história da historiografia. Revista Tempo e Argumento, Florianópolis, v. 7, n.15, p. 243 -248, maio/ago. 2015.

DOI: $\mathbf{1 0 . 5 9 6 5 / 2 1 7 5 1 8 0 3 0 7 1 5 2 0 1 5 2 4 3}$

http://dx.doi.org/10.5965/2175180307152015243 
A contar dos anos 1980, observa-se uma viva articulação dos campos científico e social, com a memória ocupando a centralidade das preocupações da disciplina histórica. Enquanto "historiador do tempo presente" (p. 140), Patrick Garcia dedica-se ao exame das comemorações e utilizações públicas da história, vista como saber privilegiado na construção de identidades sociais e políticas. ${ }^{1}$ A emergência e afirmação da história do tempo presente contribuiu para esta agenda de pesquisas em torno dos usos públicos do passado, à qual considera "necessidade imperiosa em uma sociedade democrática" (p. 178). Outro canteiro de pesquisas para o qual concorre efetivamente a história do tempo presente é o da epistemologia da história, que liga os regimes de historicidade e historiográfico contemporâneos. Agora, quando os historiadores se lançam a publicar sua própria trajetória, escrita por eles mesmos, estamos diante de uma valorização extrema da postura reflexiva. 0 autor alude mesmo a certa democratização do gênero ego-história (p. 20), que teve em Pierre Nora (1987) seu ponto de partida.

Les présents de l'historien integra a coleção "Itinéraires" (v. 6), dirigida por Patrick Boucheron nas "Publications de la Sorbonne". O objetivo da coleção é a publicação de uma peça do dossiê de defesa da "Habilitation à diriger des recherches" (HDR)2, a parte relativa à “Memória de síntese das atividades científicas" dos candidatos ao diploma. A HDR, que desde 1984 veio substituir a antiga "thèse d’État", é atualmente o mais alto título do sistema universitário francês, o qual permite ao seu portador candidatar-se ao cargo de professor universitário e diretor de tese. Este memorial, contudo, não possui maior precisão normativa (p. 14), o que acaba por favorecer o debate em torno de sua constituição e possíveis usos. Boucheron, por exemplo, deplora as tentativas de ego-história. Refere-se aos memoriais como "literatura cinzenta", 3 pois que destinados originalmente à leitura de um júri - de certa forma, em contradição com a iniciativa de dirigir a coleção.

\footnotetext{
${ }^{1}$ A ilustração da capa é, neste sentido, bastante expressiva. Trata-se da reprodução de uma aquarela, "Transfert des cendres d'André Malraux" (Patrick Legrand, 1996), que representa a cerimônia de "panteonização" do escritor e ministro de Estado em matéria cultural, André Malraux (1901-1976). O autor publicou estudo a respeito: GARCIA, P. Jacques Chirac au Panthéon. Le transfert des cendres d'André Malraux (23 novembre 1996). Sociétés \& Représentations, $n^{\circ} 12,2001$, p. 205-223.

${ }^{2}$ As traduções, pelo autor desta resenha, são livres. Em alguns casos, dos títulos, designativos e expressões, optou-se por manter os termos originais - postos entre aspas -, em razão da especificidade de seu contexto.

${ }^{3}$ BOUCHERON, P. Faire profession d'historien. Paris: Publications de la Sorbonne, 2010 (Collection Itinéraires), p. 186.
} 
Patrick Garcia sustentou sua HDR em 2011, diante de P. Ory, C. Grataloup, F. Hartog, B. Jewsiewicki, H. Rousso e J-F. Sirinelli. O dossiê era composto, além do memorial, de um ensaio inédito, "Grammaires de l'incarnation: les présidents de la République et l'histoire (19582007)", e uma coletânea dos artigos produzidos ao longo da carreira. Seu "memorial” vem a público, portanto, com o título Les présents de l'historien, que exprime uma trajetória assumidamente posta em coerência a posteriori, mas não por isso incontingente. $\mathrm{O}$ título denota, então, a inteligibilidade de sua trajetória em presentes entrelaçados (p. 166). Esta estratégia é evidenciada também na divisão do livro em três partes principais, que, embora comportem algum sentido sempre necessário, quase nada possuem de estritamente retilíneas.

Em “Da política à história do político", primeiro capítulo, o autor aponta que lhe parece indiscutível o gosto pela história ter sido contraído através das atividades políticas, ainda que presentemente a escreva não para servir às suas convicções, antes para interrogá-las (p. 22). Em 1986, foi aceito no doutorado por Michel Vovelle - de quem se aproxima também em razão de afinidades políticas -, para trabalhar, curiosamente, a respeito de "um evento que não tinha ainda acontecido", as comemorações do bicentenário da Revolução Francesa (p. 38). Seria o doutorado, concluído em 1994, o momento de definição integral pela disciplina histórica e ruptura com o Partido Comunista francês (p. 39). Assume, então, outra forma de militância, intelectual (p. 45).

O segundo capítulo, “Lugares de História”, concentra-se na pluralidade de seus “lugares institucionais", seguindo a fórmula de Michel de Certeau. Refere-se primeiramente a um trabalho coletivo em torno da revista EspacesTemps. Seria o "polo historiador" da revista o local de nascimento de uma associação intelectual, à qual se refere pelo acrônimo "DDG". Trata-se da parceria com C. Delacroix e F. Dosse (p. 55). Em 1998, eles investem em uma aproximação com o "Institut d'Histoire de Temps Présent” (IHTP/CNRS), que passa a alocar o seminário "Figuras contemporâneas da epistemologia da história" - em atividade permanente; este seminário deu origem a publicações relevantes. ${ }^{4}$ A partir da experiência e das necessidades do ensino constatadas no "Institut Universitaire de Formation des Maîtres"

\footnotetext{
${ }^{4}$ É o caso das obras Michel de Certeau, les chemins d'histoire (Éditions Complexe, 2002), com Michel Trebitsch; Paul Ricoeur et les sciences humaines (La Découverte, 2007); Historicités (La Découverte, 2009).
} 
(IUFM) de Versailles - mais tarde incorporado à Université de Cergy-Pontoise - veio a público (1999) o trabalho coletivo "Correntes Históricas na França” (trad. Ed. FGV, 2012). O grupo, mais Nicolas Offenstadt, também coordenou significativa obra de referência: "Historiographies: concepts et débats" (2011, 2 vols.). Esta se pretende uma atualização do único dicionário historiográfico até então disponível em língua francesa, ademais, “dicionário de uma escola [dos Annales]" (p. 61), de André Burguière (1986). Garcia, enfim, define seus “lugares de história” (EspacesTemps, “DDG”, IUFM, IHTP) como frágeis ou mesmo marginais. Por exemplo, associado ao IHTP, mas não pesquisador efetivo do organismo financiador, o CNRS, tem aí uma participação estritamente intelectual (p. 66). Diz apreciar, contudo, a liberdade proporcionada por esta "institucionalização fraca” (p. 87).

“Campos, posições e desafios" é o terceiro capítulo, consagrado aos temas e objetos de pesquisa. Simultâneos, e não sucessivos, derivam dos lugares e projetos que correm ao largo, ora se cruzando, ora em paralelo (p. 90). São eles, principalmente, a epistemologia da história, em processo atual de plena inscrição da historiografia em primeiro plano no conjunto maior da disciplina histórica (p. 125-6). Igualmente, a evolução da comemoração aos usos públicos do passado, desde a sua tese, passando pelo estudo das cerimônias recentes de “panteonização", até o seu dossiê de HDR sobre o uso da história em discursos oficiais pelos presidentes da $\mathrm{V}^{\mathrm{a}}$. República. Neste ponto, constata o abismo entre as interpretações de historiadores profissionais e as leituras da história para uso político, o que, mesmo descartando o monopólio do passado pelos historiadores, suscita diversas problematizações (p. 136). Enfim, e especialmente, a história do tempo presente, noção com a qual identifica a coerência de seu trabalho e sua posição como historiador. Empenha-se em um ensaio de genealogia da noção, no fito de refutar algumas críticas - notadamente de Antoine Prost, que Ihe recusa qualquer particularidade epistemológica. Garcia, porém, depende bastante das teses de Henry Rousso (La hantise du passé, 1998), para quem a história do tempo presente é a dos usos presentes do passado, sobretudo de um passado que, na palavra e experiência dos indivíduos viventes, permanece atuante sobre a memória coletiva (p. 147). Neste sentido, é notável a sua difusão global, no desafio de historicizar passados traumáticos recentes, como é o caso da América Latina (p. 158). Embora não apresente uma definição própria, sublinha que 
se trata da forma de escrita da história que, inscrita em campo de tensões, além de privilegiar a postura reflexiva, mais efetivamente contabiliza as relações passado/ presente (p. 171).

A obrigação de produzir estes memoriais pelos candidatos à HDR, o autor a vê como oportunidade de confrontação com a chamada ego-história ${ }^{5}$. Além disso, e sobremaneira, a análise do conjunto destes memoriais é considerada fonte incomparável para uma cartografia da comunidade historiadora, "precioso aporte à sociologia do métier de historiador" (p. 20). Reside nessa consciência, a meu ver, o valor central do livro. O seminário "escrita de si dos historiadores", no IHTP, ${ }^{6}$ procura atualmente realizar esta ambição. Problematiza-se aí a inscrição das evoluções historiográficas desde os anos 1980; a estruturação da profissão em termos de posições institucionais e redes de sociabilidade; ou, ainda, a memória disciplinar mobilizada nos memoriais.

Privilegiei aqui, em lugar de resumo exaustivo, compreender o lugar do livro e a estratégia de entrelaçamento de presentes, coerente com a démarche científica e a identidade profissional específica reivindicada pelo autor. O leitor depara-se frequentemente com o inusitado, os acasos. Também com a autojustificativa das razões intelectuais que presidiram suas obras, engajamentos e sociabilidades. Um bom roteiro, enfim, aos jovens pesquisadores em formação e a todo aquele interessado em melhor conhecer algumas particularidades da disciplina no sistema universitário francês.

Dada a vazão da subjetividade proporcionada pela escrita de si, estamos distantes de uma "literatura cinzenta”. É indisfarçável, por exemplo, a comoção com que o autor relembra as participaçõos de R. Koselleck e P. Ricoeur no seminário do IHTP (p. 57). A proposta de servir à sociologia da profissão, ou à história da historiografia (p. 17), desmancha qualquer suposição de mero intento narcísico. Não desfaz, contudo, a necessidade de inscrição em prática e tradição específica, nem certa projeção subentendida, expedientes que parecem quase incontornáveis na historiografia.

\footnotetext{
${ }^{5} \mathrm{~F}$. Dosse sugere a ideia de um desenvolvimento involuntário do gênero a partir dos memoriais de HDR. DOSSE, F. Pierre Nora: homo historicus. Paris: Perrin, 2011, p. 389.

${ }^{6}$ Entre 2013 e 2015 o seminário "Figuras contemporâneas da epistemologia da história” abriga o programa "Histinéraires: la fabrique de l'histoire telle qu'elle se raconte" (ANR), que associa o Centre Georges Chevrier (Dijon), o IHTP (Paris), o LARHRA (Grenoble-Lyon) e TELEMME (Aix-Marseille)” em ampla investigação sobre a "escrita de si dos historiadores". Cf. http://crheh.hypotheses.org/290
} 
Recebido em: 30/03/2015 Aprovado em: 05/08/2015

Universidade do Estado de Santa Catarina - UDESC Programa de Pós-Graduação em História - PPGH

Revista Tempo e Argumento Volume 07 - Número 15 - Ano 2015 tempoeargumento@gmail.com 